\title{
Repressão ao contrabando no Apa. Instruções. 1917
}

Instrucções para o serviço de repressão de contrabando na fronteira do Apa, no Es-tado de Matto Grosso, organizado pela Delegacia Fiscal do mesmo Estado. (Approvadas por despacho do Ministerio da Fazenda de 12 de Março de 1917, conformecommunicação da Directoria do Gabinete pela Ordem n. 26, de 19 do mesmo mez).

\section{CAPÍTULO I}

Art. $1^{\circ}$ - O serviço de repressão do contrabando na fronteira do Apa, no sul do Es-tado, zona limitrophe com a Republica do Paraguay, establecido em 1898, em virtude a Lei $n$....de 16 de Dezembro de 1897, tem por fim impedir a entrada de mercadorias e quaes-quer generos sujeitos ao pagamento de direitos de importação sem que hajam sido despa-chados pelas Mesas de Rendas de Porto Murtinho e de Bella Vista, e bem assim a sahida de animaes ou qualquer producto de exportação do Estado, obrigados ao imposto respecti-vo sem que este tenha sido satisfeito nas referidas estações ou noutras igualmente habilita-das para esse fim.

Art. $2^{\circ}$ - A acção fiscal e direcção do servió serão exercidas em toda a linha diviso-ria que constitúe a fronteira do Apa, a partir da fóz deste rio, na margem esquerda do Pa-raguay, até ao salto das Sete Quedas, no rio Paraná, passando pela cabeceira do Estrella, Ponta Porã, Nhu-Verá e Ipehum, na serra de Maracaju, seguindo sempre as divisas com a referida Republica, estabelecidas em 1874, conforme o tratado de limites de que trata o Decreto n. 4911, de 27 de Março de 1872.

Art. $3^{\circ}$ - Aacção fiscal extende-se a todas as cidades, villas, povoados, localidades e fazendas que, proximas ou afastadas da linha de fronteira, entretenham communicações com a mesma, por ella fazendo transito de mercadorias e quaesquer generos. 


\section{CAPÍTULO II}

Direcção do serviço

Art. $4^{\circ}$ - Nos lgares em que houver repartição aduaneira, a direcção do serviço de repressão do contrabando será ejercida pelo chefe da repartição, que superintenderá todo o serviço da respectiva circumscripção fiscal e direcção dos guardas.

Art. $5^{\circ}$ - O serviço de repressão do contrabando em toda a fronteira do Apa, que se divide em duas secções inmediatamente subordinadas ás Mesas de Rendas de Bella Vista e Porto Murtinho, a cujos Administradores compete a direcção respectiva nos limites de sua jurisdicção, será superentendido pela Delegacia Fiscal.

Art. $6^{\circ}$ - A primeira decção pertence a jurisdicção da Mesa de Rendas de Porto Murtinho e a segunda a de Bella Vista.

Art. $7^{\circ}$ - A jurisdicção da Mesa de Rendas de Porto Murtinho para os effeitos da fiscalização, repressão do contrabando e arrecadação de rendas comprende toda a linha divisoria, a zona respectiva, desde a fóz do Apa á margen directa do Caracol, afluente do mesmo rio, e a da Mesa de Rendas de Bella Vista, toda a linha a começar a amrgem es-querda do rio Caracol, até o salto das Sete Quedas, no rio Paraná.

Art. $8^{\circ}$ - Pertencem á primeira secção os actuaes pontos guarnecidos por destaca-mentos: Fóz do Apa, Bananal, Cachoeirinha, Cachoeira, S. Carlos, Sucury e Espirito San-to; e á segunda secção os seguintes: Veracuê, Cancha, Palmeira, Castro Pereira, Pinto Leque, Casimiro, Oliva, Itá, S. Bento, Estrella, Ponta Porã, Nhu Verá e Ipehum.

\section{CAPITULO III}

\section{Pessoal}

Nomeações, demissões, licenças, substituições, penas disciplinares e vencimentos 
Art. $9^{\circ}$ - O serviço de repressão do contrabando é ejecutado por uma força de 27 guardas, denominada - CORPO DE GUARDAS FISCAES da fronteira do Apa - distribui-dos pelas duas secções, a saber:

Primeira secção (séde - Porto Murtinho) - 10 guardas, sendo um auxiliar.

Segundo secção (séde - Bella Vista) - 17 guardas, sendo um comandante peral e dois auxiliares.

Art. $10^{\circ}$ - As nomeações e demissões dos guardas da fronteira são eclusivas da competencia do Delegado Fiscal podendo os Administradores das Mesas de Rendas fazer as propostas respectivas.

Art. $11^{\circ}$ - Nos casos de demissão, deverão as propostas ser justificadas devidamen-te.

Art. $12^{\circ}$ - Tanto o logar de comandante peral como os de auxiliares, serão exerci-dos em comissão, pelos guardas de reconhecida capacidade, designados pelo Delegado Fiscal, sob propsota do da repartição a cuja jurisdicção pertencerem, devendo as propos-tas recahir de preferencia nos guardas mais antigos e conhecedores do serviço.

Art. $13^{\circ}$ - Somente por medida excepcional de real vantagem para o serviço fiscal, confirar-se-á, e ainda assim provisoriamente, o logar de auxiliar a guarda ou oficial adua-neiro do quadro das Mesas de Rendas; cumprindo que tal designação obedeça ao precepto estabelecido no artigo precedente.

Art. $14^{\circ}$ - São condições para a admissão no corpor de guardas fiscaes da frontei-ra:

a) ser brasileiro;

b) ter mais de 16 annos de idade e menos de 50;

c) saber ler e escrever;

d) ser de bom comportamento, attestado por auctoridade competente e não haver soffrido pena em consecuencia de crime infamante;

e) não achar se respondendo a processo criminal ou administrativo;

f) não ser suspeito aos interesses do fisco e nunca ter-se nvolvido, directa ou indi-rectamente em processo de contrabando; 
g) não haver sido eliminado de qualquer corporação estadual ou federal como elemento pernicioso ou com nota de indisciplina.

Art. $15^{\circ}$ - Para entrar em exercício das funcções de guarda da fronteira, o nomeado se obrigará, mediante termo de compromisso, ao exacto cumprimento dos seus deveres.

Art. $16^{\circ}$ - Os guardas da fronteira, inclusive o comandante peral e auxiliares, são passíveis das seguintes penas disciplinares, por faltas, omissões, abusos e delictos que commetterem, além de outras de responsabilidade criminal em que posma incorrer:

a) advertencia;

b) reprehensão verbal ou por escripto;

c) serviço dobrado até tres dias;

d) suspensão até 15 dias, com perda total de vencimentos;

e) multa até 10 dias de vencimentos;

f) dispensa do commando de destacamento;

g) dispensa de outro cargo de commissão como o de comandante peral ou auxi-liar;

h) demissão;

i) expulsõ.

Art. $17^{\circ}$ - As penas declaradas no artigo anterior poderão ser impostas pelo Admi-nistrador da Mesa de Rendas a cuja jurisdicção pertencer o empregado, das letras a a f, e pelo Delegado Fiscal, das letras $g$ af.

Art. $18^{\circ}$ - A unica auctoridade competente no Estado para conceder licença ao pes-soal do corpo de guardas da fronteira é o Delegado Fiscal.

Art. $19^{\circ}$ - Em caso de molestia, devidamente attestada, e precedendo informação do Administrador da Mesa de Rendas, o Delegado Fiscal poderá conceder até 30 dias de lice-ça, percebendo o licenciado apenas o ordenado do seu cargo.

Art. $20^{\circ}$ - O Administrador da Mesa de Rendas, em caso de doença de gravidade comprovada, poderá justificar faltas dos guardas de sua juris- 
dição, devendo dar conheci-mento á Delegacia Fiscal si excederem de 8 dias.

Art. $21^{\circ}$ - Si a molestia que privar o guarda de compareci mento fôr adquirida em consequencia de ferimentos e lesões em acto de repressão de contrabando, poderá ser con-cedida ao empregado, licença até 6 mezes, sem perda de gratificação.

Art. $22^{\circ}$ - Nos impedimentos do commandante geral, de pequena duração, poderá o Administrador da Mesa de Rendas de Bella Vista designar um auxiliar ou guarda, de re-conhecida capacidade, para substituil-o, dando desse acto conhecimento á Delegacia Fis-cal.

Art. $23^{\circ}$ - Si a ausencia do commandante geral fôr por motivo de serviço especial ou licença, que o afaste do serviço do cargo por mais de 15 dias, deverá o Administrador communicar á Delegacia Fiscal, propondo o empregado que tiver de substituil-o interina-mente.

Art. $24^{\circ}$ - A regra estabelecida para a substituição do commandante geral no artigo antecedente, deverá ser observada pelos Administradores das Mesas de Rendas, quanto aos auxiliares de sua jurisdicção.

Art. $25^{\circ}$ - O pessoal do - Corpo de Guardas Fiscaes da fronteira do Apa - percebe-rá os vencimentos constantes da tabella que poderá ser alterada annualmente em vista do credito que for distribuido para as despezas da subconsignação pela qual é custeado o serviço de repressão do contrabando.

Art. $26^{\circ}$ - Dos vencientos dos guardas consideram-se ordenado 2/3, e gratificação $1 / 3$.

\section{CAPITULO IV}

Attribuições e deveres

Art. $27^{\circ}$ - Ao commandante geral incumbe:

a) percorrer frequentemente toda a linha divisoria, fiscalizando os postos e desta-camentos das duas secções, agindo de forma que o pessoal do corpo de 
guardas se encon-ter sempre vigilante nos postos fiscaes competentes e se mantenha no desempenho de suas obrigações;

b) cumprir e fazer cumprir as ordens que lhe forem dadas pelos Administradores das Mesas de Rendas de Bella Vista e Porto Murtinho, com relação ao pessoal das secções respectivas;

c) levar ao conhecimento dos Administradores das Mesas de Rendas as irregulari-dades, faltas ou quaesquer factos inconvenientes ao serviço, que observarem em sua via-gem de percurso á linha da fronteira, expondo-os com minucia e propondo as medidas que lhe parecerem acertadas em proveito do serviço e dos interesses fiscaes;

d) examinar o material, armamento e municção a cargo dos postos e destacamentos dos guardas, principalmente sobre sua conservação;

e) designar em caso urgente, nas suas viagens pela fronteira, os guardas que devem proceder a diligencias e apprehensões de contrabando, do que dará conhecimento á Mesa de Rendas competente;

f) requisitar, em codições de rigorosa necessidade,força militar para garantir a acção fiscal do posto ou destacamento que tenha de agir sem perda de tempo, em apprehensões de con-trabando, o que levará inmediatamente ao conhecimento da estação fiscal competente;

g) apresentar mensalmente um mappa dos guardas das duas secções, com declaraç-ão do destino, commissões em que se acharem e demais informações necessárias;

h) organizar as folhas de vencimentos dos guardas da segunda secção e apresental-as até o dia 10 de cada mez ao Administrador da Mesa de Rendas de Bella Vista, para o devido pagamento;

i) proceder pessoalmente ao pagamento dos vencimentos do pessoal quando lhe fôr determinado pela respectiva repartição, devendo no tocante á primeira secção, ser enca-rregado dessa incumbencia o guarda auxiliar da jurisdição de Porto Murtinho, que nesse caso organizará a respectiva folha;

j) representar ao chefe da estação compretente sobre faltas e abusos de que tiver conhecimento, commettidas não só pelo pessoal fiscal como por particulares, quando estes visarem prejudicar o serviço; 
k) requisitar um guarda ou mais de um, segundo a necessidade, para acompanhal-o nas viagens periodicas de fiscalização e noutras que, com objecto de serviço, tenha de em-prehender pela fronteira;

l) desempenhar outras commissões e serviços que lhe forem confiados pelo Adminis-trador da Mesa de Rendas de Bella Vista, a que está inmediatamente subordinado.

\section{Dos auxiliadores}

Art. $28^{\circ}$ - Os guardas auxiliares immediatos do commandante geral são trêa, e têm residencia, respectivamente, em S. Carlos ( $1^{a}$ secção), Ponta Porã e Ipehum (2 $2^{a}$ secção).

Art. $29^{\circ}$ - Compete aos auxiliares:

a) ajudar o commandante geral nos serviós de fiscalização e direcção do pessoal;

b) dirigir com zelo e actividade o destacamento fiscal a seu cargo, exercendo, com o pessoal respectivo, rigorosa fiscalização na zona pertencente ao seu posto;

c) escalar diariamente ou como convenha mais á fiscalização os guardas para o serviço de rondas, guarnições e sentinellas, nos pontos accessiveis á passagem do contra-bando, não só na localidade em que fôr situado o destacamento, como fóra onde fôr neces-saria a acção fiscal;

d) apprehender e fazer apprehender, autoando os delinquentes, os generos, merca-dorias e animaes que, sem prévio pagamento de direitos, se considerarem contrabando nos termos da legislação vigente;

e) communicar directamente ao Administrador da Mesa de Rendas que estiverem subordinados ou ao commandante geral si este estiver presente, qualquer facto que exija providencia superior em proveito dos interesses da fiscalização;

f) solicitar da auctoridade competente, em caso extraordinario, o logar do posto a seu cargo, força militar para garantia de apprehenção de contrabando ou de outra qual-quer diligencia urgente em proveito da Fazenda Nacional; 
g)arrecadar rendas de exportação, emquanto vigorar o accôrdo contracto com o governo estadual mediante taloes devidamente authenticados que lhes forem fornecidos pela Mesa de Rendas;

h) executar todo e qualquer serviço que lhes fôr distribuido pelo chefe da repartição que estiverem subordinados.

Dos commandantes de destacamentos

Art. $30^{\circ}$ - Aos commandantes ou encarregados de destacamentos além das obrigaç-ões que lhes cabem como guardas, incumbe:

a)manter em bôa ordem e disciplina o pessoal do destacamento a seu cargo;

b)dirigir, de accôrdo com as ordens que receberem do commandante geral ou auxi-liares, a fiscalização no ponto de sua parada;

c) levar ao conhecimento do auxiliar a que estiver inmediatamente subordinado, os factos que exigirem acção superior.

Dos guardas

Art. $31^{\circ}$ - Aos guardas da fronteira compete:

a) desempenhar com zelo e actividade os serviços de fiscalização inherentes ao car-go, taes como: rondas, sentinellas, apprehensões, buscas, vigilancias e outros para que forem designados pelo Administrador da Mesa de Rendas, Commandante Geral ou Auxi-liares;

b) seguir promptamente para os pontos que lhes forem destinados, assim como para os logares onde se lhes tenha confiado alguma commissão ou diligência;

c) prestar com solicitude as informações e esclarecimentos que lhes forem exigidos por seus superiores, aos quaes, quando tiverem conhecimento de qualquer facto prejucidial aos interesses da fiscalização, farão expontaneamente as communicações necessarias; 
d)substituir os auxiliares nos ligeiros impedimentos destes por ordem de antiguida-de, ou interinamente, por designação regulamentar;

e) cumprir com exactidão as ordens e recomendações que lhes forem dadas por seus superiores;

f) conservar em bôa ordem o armamento e munição que lhes forem entregues sendo responsaveis pelo seu extravio ou estrago;

g)ter um cavallo para sua montaria, devidamente arreiado, para as diligencias que tiverem de effectuar.

\section{CAPITULO V}

Disposições diversas

Art. $32^{\circ}$ - Os Administradores das Mesas de Rendas de P. Murtinho e Bella Vistas, de conformidade com as disposições da Nova Consolidação das Leis das Alfandegas e Me-sas de Rendas, e mais regulamentos em vigor são os competente para dirigir o serviço de repressão do contrabando na zona de sua jurisdicção fiscal, e consequentemente, os chefes do pessoal do Corpo de Guardas da fronteira do Apa, das $1^{a}$. e $2^{a}$ secções respectivamen-te.

Art. $33^{\circ}$ - Em todo e qualquer caso não previsto nestas Instrucções, deverão os Ad-ministradores das Mesas de Rendas dirigir-se ao Delegado Fiscal.

Art. $34^{\circ}$ - Quando, por designação do Delegado Fiscal, fôr encarregado funcciona-rio de fazenda para inspeccionar o serviço de fiscalização na fronteira, o que se fará an-nualmente, os Administradores das Mesas deRendas lhe prestarão todo auxilio e informaç-ões precisas para o bom éxito da commissão.

Art. $35^{\circ}$ - O inspector, no desempenho de sua commissão, poderá agir como chefe do serviço, tomando providências de sua iniciativa ou de accôrdo com as instrucções que receber do Delegado Fiscal, não só quanto ao pessoal do Corpo de Guardas, como quanto aos logares e postos fiscaes.

Art. $36^{\circ}$ - O inspector fiscal communicará aos Administradores das Mesas 
de Ren-das as medidas que haja tomado e que forem necessarias á repressão do contrabando e bôa arrecadação das rendas publicas.

Art. $37^{\circ}$ - Nenhum vencimento, gratificação ou vantagem especial se abonará em face destas Instrucções, sinão em virtude de ordem da Delegacia Fiscal excepto os venci-mento constantes da tabella junta.

Art. $38^{\circ}$ - Os empregados do serviço de repressão do contrabando na fronteira do Apa, cujos vencimentos serão pagos pelo crédito da sub-consignação competente da verba - Delegacias Fiscaes - nenhuma regalia terão quanto á estabilidade nos cargos, e serão conservados emquanto bem servirem e convier aos interesses fiscaes, a juizo da Delegado Fiscal.

Art. $39^{\circ}$ - Os Auxiliares deverão ser substituidos ou transferidos de posto fiscal se-mestralmente, podendo permanecer nelle por mais tempo quando fôr reconhecida a vanta-gem de sua continuação.

Art. $40^{\circ}$ - Ao funccionario que exercer a comissão de inspecção de que trata o art. 34, abonar-se-á uma diaria de $10 \$ 000$ a $15 \$ 000$ arbitrada pelo Delegado Fiscal, em cujo serviço não deverá permanecer mais de tres mezes, salvo por necessidade de alguma dili-gencia de carácter urgente ou por motivo de força maior, devidamente justificados.

Delegacia Fiscal do Thesouro Nacional, em 31 de Janeiro de 1916

(Assignado) Mario B. Cardoso

Tabella de vencimentos do pessoal do serviço de repressão do contrabando na fronteira do Apa, a que se referem as presentes Instrucções

\begin{tabular}{|c|c|c|c|c|}
\hline & Vencimentos & Mensaes & & \\
\hline Pessoal & Ordenado & Gratificação & $\begin{array}{c}\text { Total } \\
\text { de cada } \\
\text { empregado }\end{array}$ & $\begin{array}{l}\text { Gratificação } \\
\text { especial de } \\
\text { commando }\end{array}$ \\
\hline $\begin{array}{c}\text { Subordinados á Mesa de Rendas } \\
\text { de Bella Vista: } \\
17 \text { guardas } \\
\text { (sendo } 1 \text { commandante } \\
\text { e } 2 \text { auxiliares } \\
\text { Commandante geral } \\
\text { Auxiliares (2) } \\
\text { Subordinados á } \\
\text { Mesa de Rendas de P. Murtinho: } \\
10 \text { guardas } \\
\text { Auxiliar (1) }\end{array}$ & $\begin{array}{l}86 \$ 666 \\
86 \$ 666\end{array}$ & $43 \$ 334$ & $\begin{array}{c}130 \$ 000 \\
100 \$ 000 \\
50 \$ 000 \\
130 \$ 000 \\
50 \$ 000\end{array}$ & $\begin{array}{c}100 \$ 000 \\
50 \$ 000\end{array}$ \\
\hline
\end{tabular}

